\title{
Effects of total flavones from Dendranthema morifolium on vasocontraction and proliferation of vascular smooth muscle cells
}

\author{
HONG-FENG JIN ${ }^{1}$, XIAO-WEI LIU ${ }^{2}$, YI-MING TANG ${ }^{1}$, LI-JIANG TANG ${ }^{1}$, YA-LI WANG ${ }^{1}$ and CHANG-QING DU ${ }^{1}$ \\ ${ }^{1}$ Department of Cardiology, Zhejiang Hospital, Hangzhou, Zhejiang $310013 ;{ }^{2}$ Department of Cardiology, \\ The First Clinical Medical Institute of Wenzhou Medical University, Wenzhou, Zhejiang 325000, P.R. China
}

Received November 16, 2014; Accepted October 14, 2015

DOI: $10.3892 / \mathrm{mmr} .2015 .4576$

\begin{abstract}
Pharmacological studies have shown that the active components in Dendranthema morifolium exhibit protective effects against ischemia/reperfusion injury; however, its pharmacological action on blood vessels has not yet been investigated. The purpose of the present study was to assess the effects of the total flavones extracted from D. morifolium (Ramat.) Tzvel. cv. Hangju (FDM) on the vasocontraction and proliferation of vascular smooth muscle cells (VSMCs). The tension of rat thoracic aortic rings was measured using a mechanical force transducer attached to a recording system. FDM induced a dose-dependent relaxation of rings with endothelium pre-contracted by either phenylephrine $\left(\mathrm{PE} ; 10^{-6} \mathrm{~mol} / \mathrm{l}\right)$ or a high concentration of potassium chloride $(\mathrm{KCl} ; 60 \mathrm{mmol} / \mathrm{l})$. FDM did not significantly affect the vasorelaxant effects on mechanically removed endothelium. In endothelium-denuded aortic rings depolarized by $60 \mathrm{mmol} / \mathrm{KCl}$, FDM inhibited the contraction induced by $\mathrm{Ca}^{2+}$. FDM reduced the transient contraction caused by $\mathrm{PE}$ in a $\mathrm{Ca}^{2+}$-free solution, but did not affect the contraction induced by phorbol ester. Furthermore, FDM inhibited the proliferation of VSMCs with or without growth stimulation by insulin. In conclusion, that the vasorelaxation induced by FDM in rat aortic rings is not dependent on the endothelium but is mediated via a reduction of the influx of extracellular $\mathrm{Ca}^{2+}$ through the voltage-dependent and receptor-operated channels and via the inhibition of the release of intracellular $\mathrm{Ca}^{2+}$ in VSMCs. The anti-proliferative activity of FDM suggests that it may be beneficial in inhibiting atherosclerosis.
\end{abstract}

\section{Introduction}

Dendranthema morifolium (Ramat.) Tzvel. cv. Hangju of the genus Chrysanthemum and the Asteraceae family is

Correspondence to: Mr. Chang-Qing Du, Department of Cardiology, Zhejiang Hospital, 12 Lingying Road, Hangzhou, Zhejiang 310013, P.R. China

E-mail: ddcq82@hotmail.com

Key words: Dendranthema morifolium, total flavones, aorta, vascular smooth muscle cells, vascular activity widely used in south China, either as a fragrant floral tea or as an anti-inflammatory herb in Traditional Chinese Medicine. According to component analysis, D. morifolium contains various nutrients, vitamins $\mathrm{A}$ and $\mathrm{B}$, and flavonoids $(1,2)$. The main flavonoid components include luteolin-7- $O$ - $\beta$-D-glucoside, apigenin-7- $O-\beta-9$ D-glucoside, acacetin-7- $O$ - $\beta$-D-glucoside and anthocyanins $(1,3)$. It has been reported that these components have a hypotensive effect in rats under normal conditions (4) and increase the contractility and the coronary flow in isolated and re-perfused rat hearts, thereby protecting the heart against ischemia/reperfusion injury $(5,6)$. However, to the best of our knowledge, the possible pharmacological effects of $D$. morifolium components on vessels and the underlying mechanism of action have not been studied. The present study hypothesized that total flavones extracted from D. morifolium (Ramat.) Tzvel. cv. Hangju (FDM) may have a direct relaxant effect on vasculature. The vasorelaxant effects of FDM and the potential underlying mechanisms of action were therefore investigated.

As a cluster of cardiovascular risk factors, the metabolic syndrome is increasingly being recognized as an important factor in the pathophysiological mechanisms underlying atherosclerosis and is a target of therapies (7). The metabolic syndrome is also termed syndrome of insulin resistance. Insulin can stimulate the over-proliferation of vascular smooth muscle cells (VSMCs) through the mitogen-activated protein kinase (MAPK) pathway and the phosphatidyl inositol-3 kinase (PI3K)-Akt pathway (8). The over-proliferation of VSMCs is one of the key factors in atherosclerosis and the restenosis following percutaneous transcoronary angioplasty $(9,10)$. It has been reported that the flavones and flavonoids extracted from other plants inhibit the proliferation of VSMCs and leiomyomal cells $(11,12)$. Therefore, the present study examined the effects of FDM on the proliferation of VSMCs.

\section{Materials and methods}

Drugs and chemicals. Acetylcholine (ACh), phenylephrine (PE) and phorbol 12,13-diacetate were purchased from Sigma-Aldrich (St. Louis, MO, USA). FDM was prepared by extraction (with $70 \%$ ethanol) of the dried flowers of D. morifolium (Ramat.) Tzvel. cv. Hangju, which were obtained from Tongxiang City (China), as described in a previous study (13). The FDM was identified by Professor Huidi Jiang (Department 
of Pharmaceutical Analysis, College of Medicine, Zhejiang University, Hangzhou, China).

Preparation of rat aortic rings. Male Sprague Dawley (SD) rats (weight, 240-300 g; age, 6-8 weeks) were purchased from the Animal Center, Zhejiang Academy of Medical Sciences (Hangzhou, China). All procedures were performed in accordance with the Guidelines for the Care and Use of Laboratory Animals and the experimental protocol of the present study was approved by the ethics committee of Zhejiang University. Rats were anesthetized with chloral hydrate $(0.4 \mathrm{~g} / \mathrm{kg}$ intraperitoneally (i.p.); Shenggong Biotech Co., Shanghai, China) and sacrificed by decapitation. Thoracic aortas were immediately harvested and maintained in a Krebs solution with the following composition: $118 \mathrm{mmol} / 1 \mathrm{NaCl}, 25 \mathrm{mmol} / \mathrm{l} \mathrm{NaHCO}{ }_{3}, 1.2 \mathrm{mmol} / \mathrm{K} \mathrm{KH}_{2} \mathrm{PO}_{4}$, $1.2 \mathrm{mmol} / 1 \mathrm{MgSO}_{4}, 4.7 \mathrm{mmol} / 1 \mathrm{KCl}, 1.25 \mathrm{mmol} / \mathrm{l} \mathrm{CaCl}_{2}$ and $10 \mathrm{mmol} / \mathrm{l}$ glucose (Shenggong Biotech Co.) at $4^{\circ} \mathrm{C}$. Aortas were cleared of adipose and connective tissue and then cut into $3 \mathrm{~mm}$-wide rings. A forceps was inserted into the lumen of the aortic ring and the endothelium was gently removed. Rings were suspended from an iron hook connected with a force transducer in chambers containing $10 \mathrm{ml} \mathrm{Krebs} \mathrm{solu-}$ tion at $37^{\circ} \mathrm{C}$ and with streaming of $95 \% \mathrm{O}_{2}$ and $5 \% \mathrm{CO}_{2}$ gas. The preparations were passively stretched to an optimal tension of $2 \mathrm{~g}$ after $15 \mathrm{~min}$ of equilibration with no tension. The equilibration time was $60 \mathrm{~min}$ and the Krebs solution was refreshed every $15 \mathrm{~min}$. Isometric tension was recorded by transducers connected to a recording system (MacLab, ADInstruments, Bella Vista, Australia) (14). The function of the rings was first tested in the presence of $\mathrm{KCl}(60 \mathrm{mmol} / \mathrm{l}$; Shenggong Biotech Co.) at least three times until a reproducible and stable contractile response was obtained. The function of the endothelium was tested using $\mathrm{ACh}\left(10^{-5} \mathrm{~mol} / \mathrm{l}\right.$; Shenggong Biotech Co.) to induce at least $70 \%$ relaxation pre-contraction with $\mathrm{PE}\left(10^{-6} \mathrm{~mol} / \mathrm{l}\right)$.

Culture of VSMCs and cell proliferation assay. According to the protocol of a previous study (15), chloral hydrate $(0.4 \mathrm{~g} / \mathrm{kg}$, i.p.) was used to anesthetize the male SD rats (240-300 g) prior to sacrifice by decapitation. Thoracic aortas were rapidly removed under aseptic conditions and stored in Dulbecco's modified Eagle's medium (DMEM; Sigma-Aldrich) supplemented with $10 \%$ heat-inactivated fetal bovine serum (Thermo Fisher Scientific, Inc., Waltham, MA, USA) and antibiotics $(100 \mathrm{~g} / \mathrm{ml}$ streptomycin and $100 \mathrm{U} / \mathrm{ml}$ penicillin; Sigma-Aldrich). The aortas were dissected, longitudinally opened and cut into $1 \times 1-\mathrm{mm}$ pieces following removal of the endothelium and adventitia. Cell cultures were maintained under $5 \% \mathrm{CO}_{2}$ at $37^{\circ} \mathrm{C}$ in an incubator and the medium was replaced twice a week. VSMCs were identified by a typical 'hill and valley' growth pattern and confirmed by immunofluorescence staining for $\alpha$-smooth muscle actin (Sigma-Aldrich), which is identified by green fluorescence. Confluent cells at passage 3-7 were used in all experiments.

The effects of FDM on VSMC proliferation were assayed using the 3-(4,5-dimethylthiazol-2-yl)-2,5-diphenyltetrazolium bromide (MTT) method with the MTT Cell Proliferation and Cytotoxicity Assay kit (Beyotime Institute of Biotechnology, Haimen, China) as previously described (16). The VSMCs were transferred onto a 96-well plate. After $20 \mathrm{~h}$ of culture, $15 \mu \mathrm{l}$ MTT $(5 \mathrm{mg} / \mathrm{ml})$ was added to each well and the culture medium was replaced with dimethyl sulfoxide (DMSO; Sigma-Aldrich) after $4 \mathrm{~h}$. The absorbance of every well was measured at a wavelength of $570 \mathrm{~nm}$ using a spectrophotometer (Multiskan MK3; Thermo Fisher Scientific, Inc.).

Assessment of the effects of FDM on PE- and KCl-induced vascular contraction. After a steady contraction of the aortic rings with or without endothelium induced by PE $\left(10^{-6} \mathrm{~mol} / \mathrm{l}\right)$ or $\mathrm{KCl}(60 \mathrm{mmol} / \mathrm{l})$ was achieved, FDM $(0.005,0.015,0.05$, 0.15 or $0.5 \mathrm{~g} / \mathrm{l})$, dissolved in DMSO, was cumulatively added to the Krebs solution, and the results were used to generate a concentration-response curve.

Assessment of the effects of extracellular and intracellular calcium on FDM-induced reduction of vasocontraction. In the first series of experiments, aortic rings were first incubated in $\mathrm{Ca}^{2+}$-free Krebs solution containing $50 \mathrm{~mol} / \mathrm{l}$ ethylene glycol bis(aminoethylether)-tetraacetic acid (EGTA; Shenggong Biotech Co.) and $60 \mathrm{mmol} / \mathrm{l} \mathrm{KCl}$ for $20 \mathrm{~min}$. FDM at $5 \times 10^{-2} \mathrm{~g} / 1$ was then added to the Krebs solution. In order to obtain a concentration-response curve, $\mathrm{Ca}^{2+}(0.25-5 \mathrm{mmol} / \mathrm{l})$ was then cumulatively added after $10 \mathrm{~min}$.

In the second series of experiments, after endothelium-denuded rings were incubated in $\mathrm{Ca}^{2+}$-free $\mathrm{Krebs}$ solution containing $50 \mu \mathrm{mol} / 1$ EGTA for $15 \mathrm{~min}$, PE $\left(10^{-6} \mathrm{~mol} / \mathrm{l}\right)$ was used to induce the first transient contraction. In order to allow for the restoration of intracellular $\mathrm{Ca}^{2+}$ levels, $\mathrm{Ca}^{2+}$-free Krebs solution was then replaced with normal Krebs solution and the aortic rings were incubated in normal Krebs solution for at least $40 \mathrm{~min}$. After the solution was rapidly replaced with $\mathrm{Ca}^{2+}$-free solution, the rings were incubated for another $15 \mathrm{~min}$. In order to test the effects of FDM on the second contraction induced by $10^{-6} \mathrm{~mol} / 1 \mathrm{PE}, 5 \times 10^{-2} \mathrm{~g} / \mathrm{l} \mathrm{FDM}$ was added to the solution after $15 \mathrm{~min}$.

In the third series of experiments, $2 \times 10^{-3} \mathrm{~mol} / \mathrm{l}$ caffeine (Shenggong Biotech Co.) was used to elicit a transient contractile response in endothelium-scraped rings immersed in $\mathrm{Ca}^{2+}$-free Krebs solution. $5 \times 10^{-2} \mathrm{~g} / \mathrm{l} \mathrm{FDM}$ was added to the solution and the second contraction was induced again.

Assessment of the effects of FDM on phorbol ester-induced vasocontraction. In order to induce a stable contraction in endothelium-scraped rings, $10^{-6} \mathrm{~mol} / 1$ phorbol ester (phorbol 12,13-diacetate; Shenggong Biotech Co.), an activator of protein kinase $\mathrm{C}$, was added to $\mathrm{Ca}^{2+}$-free Krebs solution containing $50 \mu \mathrm{mol} / 1$ EGTA, which the rings were immersed in. FDM was cumulatively added and the effects were recorded.

Assessment of the effects of FDM on the proliferation of cultured VSMCs. VSMCs at passages 3-7 and 70-90\% confluence in 10-cm dishes were transferred to a 96-well plate. The growth of VSMCs was arrested by incubation with serum-free DMEM for $24 \mathrm{~h}$ prior to use.

In the first set of experiments, synchronized cells were treated in the presence or absence of FDM $(0.0025,0.01,0.02$, $0.04,0.08,0.16,0.32,0.64,1.28$ and $2.56 \mathrm{~g} / \mathrm{l}$ ) for $24 \mathrm{~h}$, and the effects of FDM on the cell proliferation were assessed using the MTT method as described above. 
In the second set of experiments, cells were pre-incubated with insulin (100 nmol/l; Shenggong Biotech Co.) for $24 \mathrm{~h}$. FDM $(0.32$ or $0.64 \mathrm{~g} / \mathrm{l})$ was added to the culture medium for another $24 \mathrm{~h}$ and the proliferation of the VSMCs was assessed using the MTT method.

Statistical analysis. Values are expressed as the mean \pm standard deviation. An unpaired Student's t-test was used to compare differences between two groups. One-way analysis of variance and the Newman-Keuls test, followed by a post-hoc least-significant differences test were used to determine significant differences between multiple groups. SPSS 15.0 (SPSS, Inc., Chicago, IL, USA) was used for all statistical analyses. $\mathrm{P}<0.05$ was considered to indicate a statistically significant difference. GraphPad Prism software version 5.0 (GraphPad Software Inc., San Diego, CA, USA) was used for curve fitting.

\section{Results}

FDM exerts concentration-dependent vasorelaxant effects. After a steady contraction elicited by $10^{-6} \mathrm{~mol} / \mathrm{l} \mathrm{PE}$ was achieved, FDM was added to the aortic rings and was revealed to concentration-dependently induce vascular relaxation (Fig. 1). FDM at $0.5 \mathrm{~g} / 1$ induced complete relaxation of aortic rings in endothelium-intact as well as endothelium-denuded arotic rings (Fig. 1A-C). Furthermore, FDM caused a concentration-dependent decrease of vasoconstriction induced by $\mathrm{KCl}(60 \mathrm{mmol} / \mathrm{l})$, in endothelium-intact as well as -denuded aortic rings (Fig. 1D).

FDM reduces vasocontraction induced by extracellular and intracellular calcium. After a steady contraction of endothelium-scraped aortic rings was induced by $\mathrm{KCl}(60 \mathrm{mmol} / \mathrm{l})$ in $\mathrm{Ca}^{2+}$-free Krebs solution, $\mathrm{Ca}^{2+}$ was cumulatively added to the solution, which was shown to concentration-dependently enhance vasoconstriction. The $\mathrm{Ca}^{2+}$-induced vasoconstriction of the aortic rings was significantly inhibited by incubation with $5 \times 10^{-2} \mathrm{~g} / 1$ FDM for $10 \mathrm{~min}$ (Fig. 2A).

In another series of experiments, a contraction of endothelium-scraped aortic rings was transiently induced by $10^{-6} \mathrm{~mol} / 1$ $\mathrm{PE}$ in $\mathrm{Ca}^{2+}$-free Krebs solution. A second contraction was further induced by PE with or without $5 \times 10^{-2} \mathrm{~g} / 1$ FDM. As shown in Fig. 2, the ratio of the second to the first contraction was significantly reduced by pre-treatment with FDM for 10 min. Pre-treatment with FDM also reduced the ratio of the second to the first contraction elicited by $2 \times 10^{-3} \mathrm{~mol} / \mathrm{l}$ caffeine (Fig. 2B).

FDM does not affect phorbol ester-induced vasocontraction in a $\mathrm{Ca}^{2+}$-free solution. As shown in Fig. 3, a sustained contraction of endothelium-scraped rings evoked by phorbol ester in $\mathrm{Ca}^{2+}$-free Krebs solution with $50 \mu \mathrm{mol} / 1$ EGTA was not effected by FDM.

FDM inhibits the proliferation of cultured VSMCs. FDM dose-dependently inhibited the proliferation of cultured VSMCs. It also reduced, but did not fully abrogate, insulin-induced increases in the proliferation of VSMCs (Fig. 4).
A

Concentrations of FDM (g/l)

+Endothelium

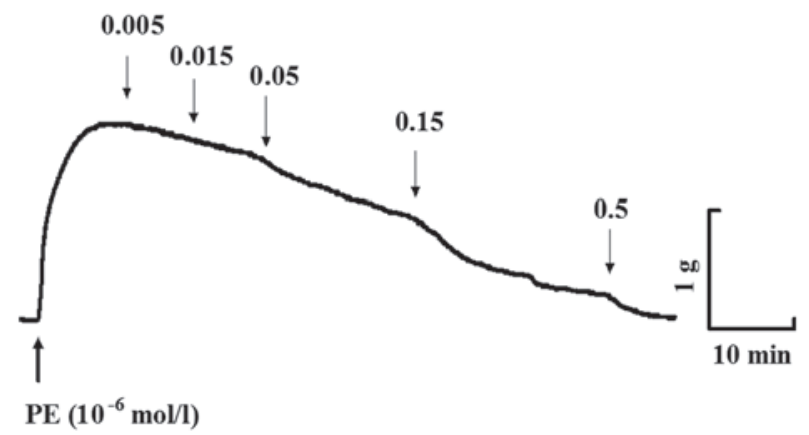

B

Concentrations of FDM (g/l) - Endothelium

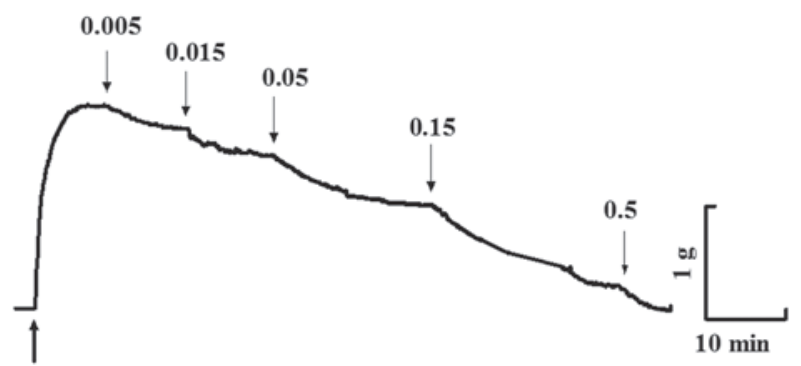

PE $\left(10^{-6} \mathrm{~mol} / \mathrm{l}\right)$

C

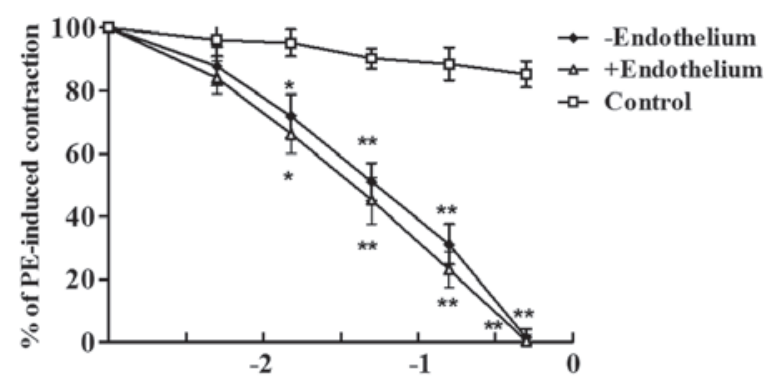

Concentrations of FDM $\log (\mathrm{g} / \mathrm{l})$

D

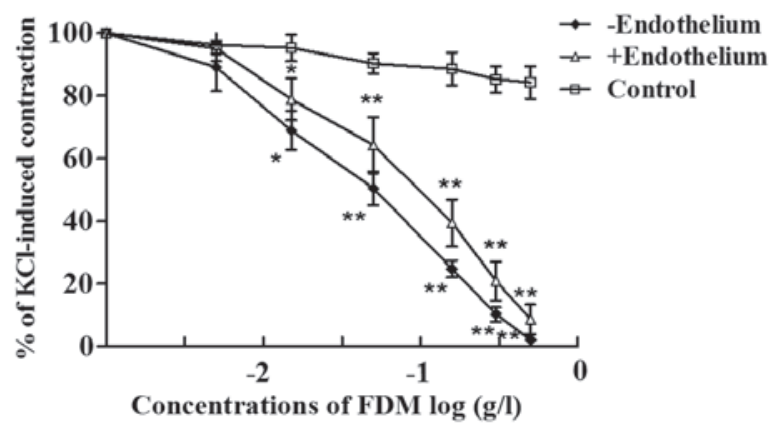

Figure 1. Concentration-dependent effects of FDM on contraction responses of endothelium-intact and endothelium-scraped aortic rings to (A-C) PE $\left(10^{-6} \mathrm{~mol} / \mathrm{l}\right)$ or $(\mathrm{D}) \mathrm{KCl}(60 \mathrm{mmol} / \mathrm{l})$. Values are expressed as the mean \pm standard deviation ( $\mathrm{n}=8$ for + endothelium group, $\mathrm{n}=9$ for - endothelium group and $\mathrm{n}=10$ for the control group). ${ }^{*} \mathrm{P}<0.05$ and ${ }^{* *} \mathrm{P}<0.01$ vs. Control. FDM, total flavones from Dendranthema morifolium (Ramat) Tzvel. cv. Hangju; PE, phenylephrine.

\section{Discussion}

Although D. morifolium is widely used in southeast China, its pharmacological action on blood vessels has not been assessed, to the best of out knowledge. The present study revealed the 
A
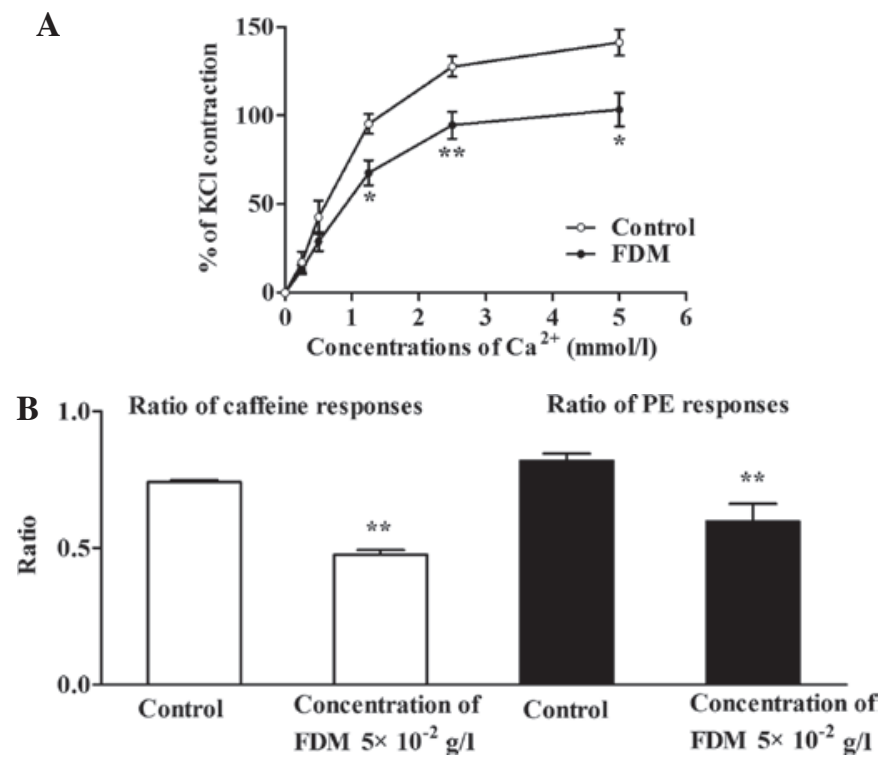

Figure 2. Effect of FDM $\left(5 \times 10^{-2} \mathrm{~g} / \mathrm{l}\right)$ on (A) the $\mathrm{Ca}^{2+}$-induced contraction of endothelium-scraped aortic rings depolarized with high $\mathrm{K}^{+}(60 \mathrm{mmol} / \mathrm{l})$ and on (B) the ratio of the contractile responses to PE $\left(10^{-6} \mathrm{~mol} / \mathrm{l}\right)$ or caffeine $\left(2 \times 10^{-3} \mathrm{~mol} / \mathrm{l}\right)$ in a $\mathrm{Ca}^{2+}$-free solution. Values are expressed as the mean \pm standard deviation ( $\mathrm{n}=5$ in $\mathrm{A}$ and $\mathrm{n}=79$ in $\mathrm{B}$ ). ${ }^{*} \mathrm{P}<0.05,{ }^{* *} \mathrm{P}<0.01$ vs. control. FDM, total flavones from Dendranthema morifolium (Ramat) Tzvel. cv. Hangju; PE, phenylephrine.

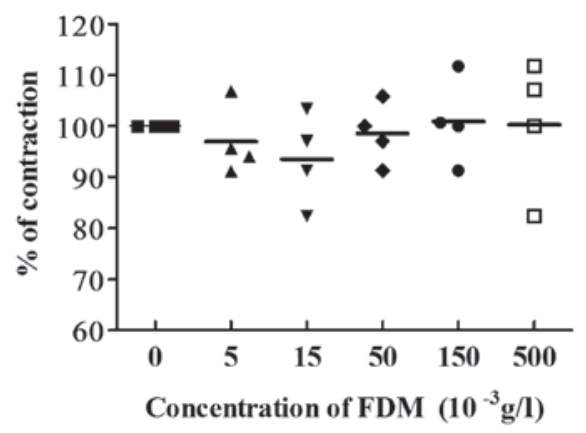

Figure 3. Effects of FDM on phorbol ester $\left(10^{-6} \mathrm{~mol} / \mathrm{l}\right)$-induced contraction in endothelium-denuded aortas in $\mathrm{Ca}^{2+}$-free solution. Each data-point represents the result for one aorta and horizontal lines represent the mean values for the respective experimental groups $(n=4)$. FDM, total flavones from Dendranthema morifolium (Ramat) Tzvel. cv. Hangju.

dose-dependent vasorelaxant effects of FDM in aortic rings from rats and investigated the potential underlying mechanisms. Furthermore, it was demonstrated that insulin-induced growth stimulation of VSMCs was inhibited by FDM.

The results of the present study revealed that FDM exerted a vascular relaxation effect and inhibited the contractions of aortic rings from rats evoked by either $\mathrm{PE}$ or $\mathrm{KCl}$. The vasodilation induced by FDM in aortic rings was shown to be endothelium-independent. Therefore, the mechanism of action of FDM is unlikely to be mediated via any endogenous vasodilators, including prostacyclin and nitric oxide from endothelial cells. Ajay et al (17) demonstrated that the release of nitric oxide was partly involved in the vascular dilation effects of most of the flavonoids. In addition, Jiang et al (18) reported that the nitric oxide synthase (NOS) activity of aortic rings was significantly increased by pre-treatment with an ethyl acetate

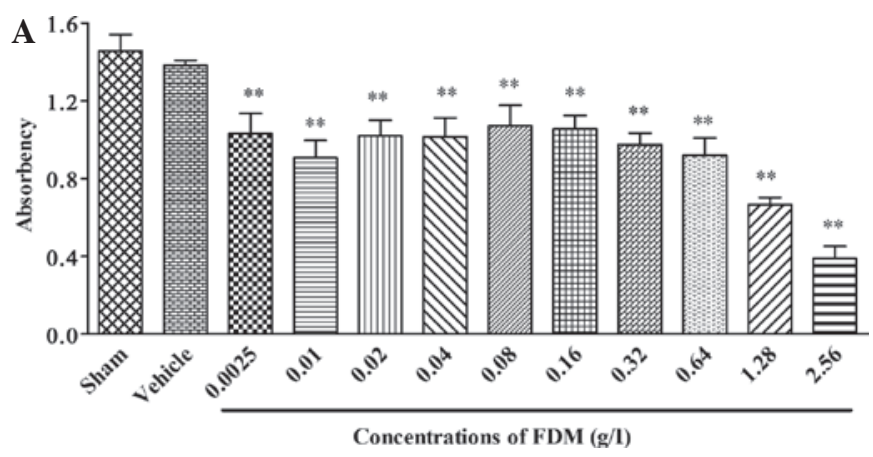

B
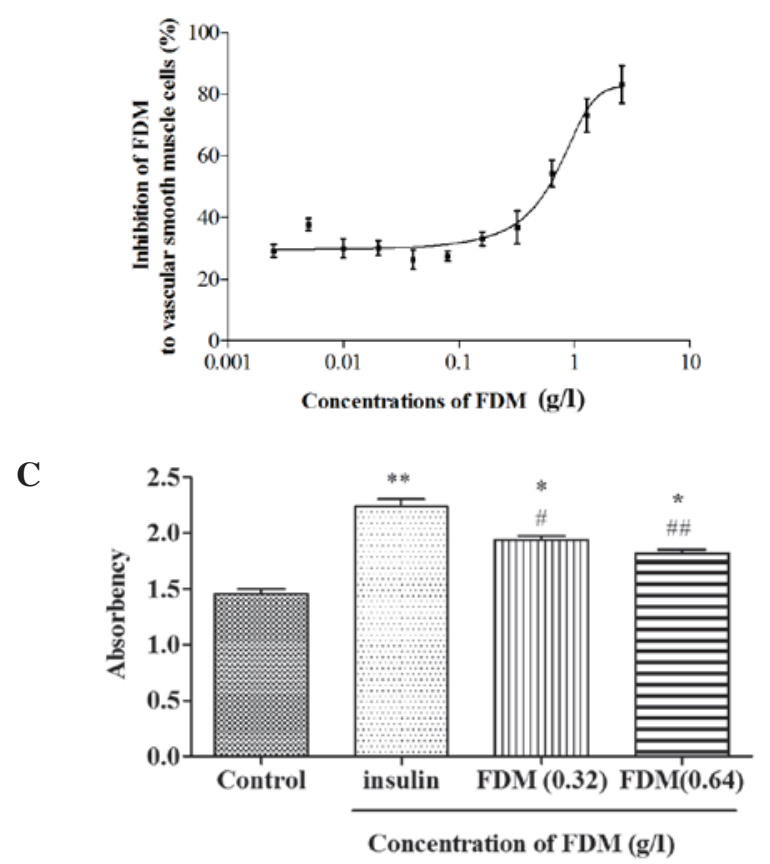

Figure 4. Effects of FDM on the proliferation of cultured vascular smooth muscle cells. (A) Absorbency of formazan at $570 \mathrm{~nm}$, which reflects cell proliferation. (B) Inhibition of VSMCs by FDM. (C) Effects of FDM on the proliferation of VSMCs stimulated by insulin $(100 \mathrm{nmol} / \mathrm{l})$. Values are expressed as the mean \pm standard deviation $(n=6) .{ }^{* *} \mathrm{P}<0.01$ vs. vehicle or control; ${ }^{\#} \mathrm{P}<0.05,{ }^{\# \#} \mathrm{P}<0.01$ vs. insulin; ${ }^{*} \mathrm{P}<0.05$ vs. control. FDM, total flavones from Dendranthema morifolium (Ramat) Tzvel. cv. Hangju; VSMC, vascular smooth muscle cell.

extract of $D$. morifolium. Whether FDM causes any variation in NO levels and/or NOS activation requires further study.

The two main types of $\mathrm{Ca}^{2+}$ channel, voltage-dependent and receptor-operated channels, can be activated by $\mathrm{KCl}$ and $\mathrm{PE}$, respectively. $\mathrm{KCl}$ causes vascular contraction mainly by inducing $\mathrm{Ca}^{2+}$ influx upon de-polarization of the cell membrane and activating voltage-dependent L-type $\mathrm{Ca}^{2+}$ channels (19).

In the present study, FDM inhibited $\mathrm{KCl}$-induced vasoconstriction in endothelium-denuded rat aortas as well as $\mathrm{Ca}^{2+}$-induced contraction of aortic rings de-polarized by $\mathrm{KCl}$, which demonstrated that FDM exerts its vascular dilation effect in part by inhibiting the voltage-dependent L-type $\mathrm{Ca}^{2+}$ channel. In addition, FDM significantly inhibited the PE-induced vascular contraction, indicating that it may also reduce influx of $\mathrm{Ca}^{2+}$ through receptor-operated $\mathrm{Ca}^{2+}$ channels.

$\mathrm{PE}$, as a selective $\alpha$-adrenoceptor agonist, induces vasoconstriction by opening receptor-operated $\mathrm{Ca}^{2+}$ channels. 
More importantly, it evokes $\mathrm{Ca}^{2+}$ release from the sarcoplasmic reticulum by activating phospholipase $\mathrm{C}$ and the generation of diacylglycerol (DG) that activates myosin light chain kinase through protein kinase $\mathrm{C}(\mathrm{PKC})$ and inositol triphosphate (IP3) (20). Therefore, the present study investigated whether FDM exerts the vasorelaxant effects through inhibiting the intracellular mobilization of $\mathrm{Ca}^{2+}$ from the sarcoplasmic reticulum and diglyceride-dependent PKC-activated myosin light chain kinase in aortic rings. In order to demonstrate that the transient contraction response to PE was mainly due to IP3-induced $\mathrm{Ca}^{2+}$ release from the sarcoplasmic reticulum, several experiments of the present study were performed in a $\mathrm{Ca}^{2+}$-free Krebs solution. FDM inhibited the PE-induced vascular contraction response in endothelium-scraped aortic rings in an extracellular $\mathrm{Ca}^{2+}$-free environment, probably due to the inhibition of intracellular $\mathrm{Ca}^{2+}$ release. However, the vascular contraction response to phorbol ester was not affected by FDM in the concentration range that relaxed aortic rings induced to contract by pre-treatment with $\mathrm{PE}$ or $\mathrm{KCl}$, suggesting that the relaxation response to FDM was not mediated through the PKC pathway.

Insulin can stimulate the overproliferation of VSMCs through the MAPK and the PI3K-Akt pathway (7). This over-proliferation is a key factor in atherosclerosis and the restenosis following stent implantation $(8,9)$. The results of the present study showed that FDM inhibited the proliferation of VSMCs under normal conditions and also inhibited insulin-induced over-proliferation. Therefore, FDM has useful implications in the clinical treatment of diseases associated with the over-proliferation of VSMCs, including as atherosclerosis and restenosis after stent implantation. Further study is required to explore the underlying mechanisms of the inhibitory effects of FDM on the proliferation of VSMCs.

In conclusion, the present study indicated that FDM exerted a vasorelaxant effect on rat aortic rings in a concentration-dependent and endothelium-independent manner. The underlying mechanism is likely to include a reduction of the $\mathrm{Ca}^{2+}$ influx by FDM through voltage-dependent as well as receptor-operated channels to inhibit the release of intracellular $\mathrm{Ca}^{2+}$ in VSMCs. It was also demonstrated that FDM inhibited the proliferation of VSMCs under normal conditions and the over-proliferation induced by insulin.

\section{Acknowledgements}

The present study was funded by grants from the Natural Science Foundation of Zhejiang province (Project for Young Scientists, no. LQ13H020004) and the Health Bureau of Zhejiang Province (no. 201353645).

\section{References}

1. Qin S and Wen X: Simultaneous determination of 6 active components in Chrysanthemum morifolium by HPLC. China Journal of Chinese Materia Medica 36: 1474-1477, 2011 (In Chinese).
2. Yu SK, Zhang Y and Wu XQ: Nutrition component and bioactivity of Dendranthema morifolium (Ramat.) Tzvel. cv. Hangju. Chinese Food and Nutrition 2: 50-51, 2002.

3. Liang YN, Guo QS, Zhang ZY, Wang SX and Wang T: Study on dynamic accumulation of secondary metabolites content and isoenzyme activity during blossoming stages in Chrysanthemum morifolium originating from Wenxian county. Zhongguo Zhong Yao Za Zhi 32: 199-202, 2007 (In Chinese)

4. Dai M, Liu Q, Li D and Liu L: Research of material bases on antifebrile and hypetensive effects of flos chrysanthemi. Zhong Yao Cai 24: 505-506, 2001 (In Chinese).

5. Jiang H, Xia Q, Xu W and Zheng M: Chrysanthemum morifolium attenuated the reduction of contraction of isolated rat heart and cardiomyocytes induced by ischemia/reperfusion. Pharmazie 59: 565-567, 2004.

6. Huang H, Guo HY and Jin HF: Effects of water extract of Dendranthema morifolium on myocardial ischemia in canines. Zhongguo Zhong Yao Za Zhi 21: 307-310, 2011.

7. Guo S: Insulin signaling, resistance and metabolic syndrome: Insights from mouse models into disease mechanisms. J Endocrinol 220: T1-T23, 2014.

8. Cersosimo E, Xu X and Musi N: Potential role of insulin signaling on vascular smooth muscle cell migration, proliferation, and inflammation pathways. Am J Physiol Cell Physiol 302: C652-C657, 2012.

9. Chen J, Dai M and Wang Y: Paeonol inhibits proliferation of vascular smooth muscle cells stimulated by high glucose via Ras-Raf-ERK1/2 signaling pathway in coculture model. Evid Based Complement Alternat Med 2014: 484269, 2014.

10. Wang K, Wen L, Peng W, Li H, Zhuang J, Lu Y, Liu B, Li X, $\mathrm{Li} \mathrm{W}$ and $\mathrm{Xu}$ Y: Vinpocetine attenuates neointimal hyperplasia in diabetic rat carotid arteries after balloon injury. PLoS One 9: e96894, 2014.

11. Xing J, Peng K, Cao W, Lian X, Wang Q and Wang X: Effects of total flavonoids from Dracocephalum moldavica on the proliferation, migration, and adhesion molecule expression of rat vascular smooth muscle cells induced by TNF- $\alpha$. Pharm Biol 51: 74-83, 2013.

12. Jiang D, Li D and Wu W: Inhibitory effects and mechanisms of luteolin on proliferation and migration of vascular smooth muscle cells. Nutrients 5: 1648-1659, 2013.

13. Jiang H, Xia Q, Xu W and Zeng M: Chrysanthemum morifolium attenuated the reduction of contraction of isolated heart and cardiomyocytes induced by ischemia/reperfusion. Pharmazie 59: 565-567, 2004.

14. Kim SH, Kang KW, Kim KW and Kim ND: Procyanidins in crataegus extract evoke endothelium-dependent vasorelaxation in rat aorta. Life Sci 67: 121-131, 2000.

15. Zhang S, Yang Y, Kone BC, Allen JC and Kahn AM: Insulin-stimulated cyclic guanosine monophosphate inhibits vascular smooth muscle cell migration by inhibiting $\mathrm{Ca} /$ calmodulin-dependent protein kinase II. Circulation 107: 1539-1544, 2003.

16. Takahashi S, Abe T, Gotoh J and Fukuuchi Y: Substrate-dependence of reduction of MTT: A tetrazolium dye differs in cultured astroglia and neurons. Neurochem Int 40: 441-448, 2002.

17. Ajay M, Gilani AU and Mustafa MR: Effects of flavonoids on vascular smooth muscle of the isolated rat thoracic aorta. Life Sci 74: 603-612, 2003.

18. Jiang HD, Cai J, Xu JH, Zhou XM and Xia Q: Endothelium-dependent and direct relaxation induced by ethyl acetate extract from Flos Chrysanthemi in rat thoracic aorta. J Ethnopharmacol 101: 221-226, 2005.

19. Ji J, Benishin CG and Pang PK: Nitric oxide selectively inhibits intracellular $\mathrm{Ca} 2+$ release elicited by inositol trisphosphate but not caffeine in rat vascular smooth muscle. J Pharmacol Exp Ther 285: 16-21, 1998.

20. Amberg GC and Navedo MF: Calcium dynamics in vascular smooth muscle. Microcirculation 20: 281-289, 2013. 